\title{
Isolante térmico fibroso: motivos de sua utilização como revestimentos de trabalho em equipamentos industriais que operam em altas temperaturas - revisão da literatura - parte I
}

\section{(Fibrous thermal insulation: reasons of its use as a wear lining in industrial equipment which work at high temperatures - a review - part I)}

\author{
D. G.M.Silva ${ }^{1}$, W. L. Vasconcelos ${ }^{2}$ \\ ${ }^{l}$ Vallourec Tubos do Brasil S.A., Av. Olinto Meireles 65, Belo Horizonte, MG, Brasil 30640-010 \\ ${ }^{2}$ Laboratório de Materiais Cerâmicos, Departamento de Engenharia Metalúrgica e de Materiais, \\ Universidade Federal de Minas Gerias, Av. Presid. Antônio Carlos 6627, Belo Horizonte, MG, Brasil 31270-901 \\ dgmsilva@yahoo.com.br,wlv@demet.ufmg.br
}

\begin{abstract}
Resumo
Durante a concepção de um projeto de revestimento refratário para equipamentos industriais, três aspectos básicos devem ser levados em consideração: eficiência energética/produtividade, emissão de $\mathrm{CO}_{2}$ e saúde/segurança ocupacional. Avaliando estas três exigências do mercado, os isolantes térmicos fibrosos apresentam importantes características que fazem com que estes produtos tenham alto valor agregado para as indústrias. Neste contexto, este trabalho visou apresentar e discutir os três cenários citados, utilizando três classes de fibras e comparando-as com revestimentos refratários comumente empregados no ramo siderúrgico.

Palavras-chave: isolante térmico, fibras cerâmicas refratárias, fibras de baixa biopersistência, fibras policristalinas, eficiência energética.
\end{abstract}

\begin{abstract}
During the development of a refractory lining project to the industry, three basic aspects must be taken into account: energy efficiency/productivity, greenhouse effect, and health \& safety. In order to evaluate these three demands from the market, fibrous thermal insulations show important characteristics that make these products with high added value to the industries. In this context, the aims of this paper were presenting, comparing and discussing the advantages and drawbacks of the fibrous thermal insulations with other refractory linings used in the industry, evaluated through the economical, environmental and occupational scenarios.

Keywords: thermal insulation, refractory ceramic fibers, biosoluble fibers, polycrystalline wools, energy efficiency.
\end{abstract}

\section{INTRODUÇÃO}

A utilização de isolantes térmicos à base de fibras refratárias merece destaque no setor metalúrgico, em especial, no ramo siderúrgico. Neste processo industrial, esses materiais são utilizados em diversos equipamentos, sendo alguns desses: sistema de distribuição de ar quente dos altos fornos, canal de corrida, regeneradores de calor, carro torpedo, tampas de panelas de aço e de gusa, distribuidor de aço e fornos de aquecimento, reaquecimento e tratamento térmico. A importância desses produtos refratários nas unidades industriais citadas está diretamente ligada a três pilares básicos de sustentabilidade das atividades fabris. $\mathrm{O}$ primeiro aspecto está relacionado ao cenário econômico, ao qual se configuram reduções no consumo de energia e aumento da disponibilidade dos equipamentos para a área produtiva; o segundo diz respeito à questão ambiental, vinculada à redução na emissão de $\mathrm{CO}_{2}$; e o terceiro e último pilar relaciona-se aos quesitos de saúde e segurança, ou seja, escolha de materiais que não tragam preocupações ocupacionais [1-3]. Dentre os vários produtos refratários utilizados na indústria siderúrgica, destacam-se os isolantes térmicos fibrosos, mais especificamente, a fibra cerâmica refratária (FCR), a fibra de silicato de metais alcalino-terrosos (AES - alkaline earth silicate wool) e a fibra policristalina (PCW - polycrystalline wool). Estes três produtos merecem destaque devido à sua importância, para as indústrias, em relação aos três cenários mencionados.

Os isolantes térmicos fibrosos são utilizados como revestimento refratário, objetivando isolar equipamentos, e são expostos a temperaturas de trabalho que podem variar entre 500 a $1700{ }^{\circ} \mathrm{C}$ [4]. As razões do emprego dos isolantes térmicos à base de fibras refratárias estão diretamente ligadas ao conjunto de propriedades químicas, físicas e especiais. Dentre estas propriedades destacam-se: baixa condutividade térmica, baixa capacidade calorífica, alta resistência ao dano por choque térmico, baixa densidade, alta resiliência e flexibilidade. Estes atributos fazem com que estes materiais 
sejam utilizados não só como revestimento permanente, mas também como revestimento de trabalho. Por possuírem baixa condutividade térmica, a perda de energia (calor) através do revestimento refratário é minimizada e, consequentemente, a eficiência energética do equipamento é potencializada. Adicionalmente, avaliando-se em conjunto os três parâmetros, condutividade térmica, capacidade calorífica e densidade, estes estão diretamente relacionados ao controle da energia interna do equipamento. Como são necessários ajustes de temperatura no forno durante o tratamento de diferentes materiais (qualidade distinta de aços), os isolantes térmicos fibrosos respondem com uma menor inércia térmica quando comparados a outros refratários; desta forma, o consumo de energia é otimizado. Avaliando o aspecto de produtividade, por apresentarem alta resistência ao dano por choque térmico, esta propriedade permite o emprego de altas taxas de resfriamento e aquecimento nos fornos, após paradas de manutenção e/ou de operação, aumentando a disponibilidade do equipamento para o processo produtivo. Os outros dois fatores, alta resiliência e flexibilidade, são importantes durante o processo de instalação e montagem do revestimento. Estas características permitem a realização de intervenções de manutenção em tempos reduzidos, aumentando a disponibilidade do equipamento para a produção.

Para as fibras policristalinas, por conta da sua estrutura cristalina, praticamente não há modificações microestruturais e morfológicas significativas a altas temperaturas, que possam contribuir na redução de seus desempenhos físicos e térmicos. As fases geralmente encontradas nas fibras PCW em temperaturas próximas a $1500{ }^{\circ} \mathrm{C}$ são mulita e coríndon, praticamente as mesmas identificadas no material in natura [5]. Contudo, a exposição prolongada das fibras, em especial as fibras vítreas FCR e AES, a temperaturas superiores a $900{ }^{\circ} \mathrm{C}$, gera modificações microestruturais e morfológicas, que contribuem diretamente na redução de suas vidas úteis [6]. Outro ponto que merece destaque é o aspecto dos riscos ocupacionais. As fibras FCRs foram consideradas possivelmente patogênicas à espécie humana por diversas entidades reguladoras, tais como: Agência de Proteção ao Meio Ambiente dos Estados Unidos (EPA), Agência Europeia de Produtos Químicos (ECA) e Agência Internacional de Pesquisa sobre Câncer (IARC). De acordo com a IARC, há evidências que comprovam o seu risco ocupacional em animais (estudos experimentais em ratos). Contudo, as evidências que poderiam comprovar o potencial de patogenicidade das fibras FCRs na espécie humana não são conclusivas [7]. Para as fibras AES, nenhuma evidência patológica em animais foi comprovada, considerando experimentos com as fibras in natura, ou seja, conforme recebidas [8-10]. Contudo, ao expor estes materiais a determinados tempos e temperaturas, modificações em suas microestrutura e morfologia são identificadas, podendo ocasionar a formação da fase cristobalita [11-16]. Esta fase polimórfica da sílica cristalina apresenta uma preocupação em potencial, uma vez que há evidências comprovadas do seu risco ocupacional em animais (estudos experimentais em ratos) e na espécie humana [17]. Já para as fibras PCW, estes materiais não foram classificados até o momento, por nenhuma regulamentação e/ou diretiva europeia, de acordo com o seu grau de patogenicidade $[18,19]$. Os fabricantes das fibras PCW creditam esta falta de classificação ao controle mais preciso das dimensões das fibras durante a fabricação. Este controle gera um produto com uma menor quantidade de material particulado considerado respirável, dentro das premissas da Organização Mundial de Saúde.

Nestes três contextos, esta revisão da literatura possui os seguintes propósitos: apresentar uma descrição da classificação dos isolantes térmicos fibrosos (vítreos e cristalinos), bem como termos utilizados segundo padrões e normas regulamentadoras; descrever os processos de manufatura e o histórico em relação ao seu desenvolvimento; apresentar aplicações convencionais na indústria siderúrgica; mostrar as vantagens ambiental e econômica de seus usos frente às composições de materiais refratários comercialmente empregados em unidades fabris; e por fim, expor problemas ocupacionais relacionados à sua utilização. Cabe ressaltar que informações relativas aos parâmetros e características de sua microestrutura, bem como o processo de transferência de energia térmica através dos três tipos de isolantes fibrosos, FCR, AES e PCW, serão tratados e discutidos no artigo revisão - parte II.

\section{CLASSIFICAÇÃO DAS FIBRAS}

As fibras podem ser classificadas de acordo com as suas características naturais ou artificiais, orgânicas ou inorgânicas, bem como em relação ao seu grau de cristalinidade [20]. Na Fig. 1 está apresentada uma visão global da classificação das fibras. Dentre as fibras naturais orgânicas destacam-se as fibras vegetais, como algodão, linho, juta, cânhamo e sisal. Para as fibras naturais

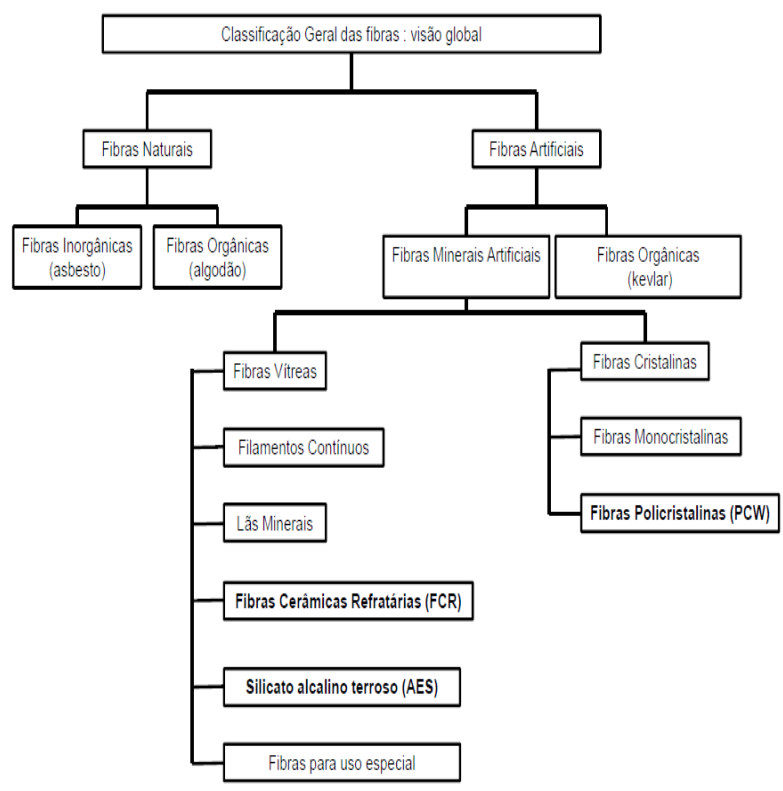

Figura 1: Classificação geral das fibras [20].

[Figure 1: General classification of fibers [20].] 
inorgânicas, têm-se alguns exemplos minerais: sepiolita, atapulgita, erionita, wollastonita e asbesto. Em particular, este último mineral apresenta importantes características, tais como: alta resistência térmica, durabilidade em meios ácidos e outros meios químicos, e baixa densidade aparente. Para as fibras artificiais orgânicas, alguns exemplos são fibras de carbono, celulose, poliéster, nylon, kevlar, etc. Para as fibras minerais artificiais ou fibras artificiais inorgânicas ou fibras inorgânicas feitas pelo homem, destacam-se fibras de vidro, lã de rocha, escória, cerâmicas refratárias (FCR), silicato de metais alcalino-terrosos (AES) e policristalinas (PCW). Para as fibras minerais artificiais, o foco deste trabalho está direcionado para três tipos de materiais, FCR, AES e PCW. De acordo com padrões europeus, estes produtos refratários também podem ser classificados como: HTIW - lãs isolantes para alta temperatura [21], HTW - lãs para altas temperaturas [22], MMMF - fibras minerais feitas pelo homem [7] e MMVF - fibras vítreas feitas pelo homem [7], sendo que para este último caso, especificamente para este artigo, apenas os materiais FCR e AES fazem parte desta nomenclatura.

Termos gerais e definições: alguns termos e definições de interesse deste trabalho, em concordância com as normas europeias, são [21, 22]: i) lã - aglomerado não direcional de fibras com distribuições variadas de diâmetro e comprimento; ii) fibra - partículas com razão entre comprimento e diâmetro superior a 3:1; iii) FCR - fibras vítreas feitas pelo homem, com orientação aleatória e composta por sílica e alumina (AFCR) ou sílica, alumina e zircônia (ZFCR); na Tabela I são apresentadas as composições químicas dessas duas fibras; iv) AES - fibras vítreas feitas pelo homem, com orientação aleatória e composta por óxidos de cálcio e magnésio em proporções superiores a $18 \%$ em massa;

Tabela I - Composição química das fibras estudadas [21]. [Table I-Chemical composition of the studied fibers [21].]

\begin{tabular}{ccc}
\hline Tipo de fibra & Componente & $\begin{array}{c}\text { Fração em } \\
\text { massa (\%) }\end{array}$ \\
\hline $\begin{array}{c}\text { AFCR } \\
\text { (aluminosilicate } \\
\text { wool) }\end{array}$ & $\mathrm{Al}_{2} \mathrm{O}_{3}$ & 46 a 56 \\
$\mathrm{SiO}_{2}$ & 44 a 54 \\
Outros óxidos & $<1$ \\
\hline ZFCR (alumino & $\mathrm{Al}_{2} \mathrm{O}_{3}$ & $<37$ \\
zirconium & $\mathrm{SiO}_{2}$ & $>48$ \\
silicate wool) & $\mathrm{ZrO}_{2}$ & $<20$ \\
& $\mathrm{Outros} \mathrm{óxidos}$ & $<1$ \\
\hline & $(\mathrm{CaO}+\mathrm{MgO})$ & $18-43$ \\
AES (alkaline & $\mathrm{SiO}_{2}$ & $50-82$ \\
earth silicate $)$ & $\left.\left(\mathrm{Al}_{2} \mathrm{O}_{3}+\mathrm{TiO}_{2}+\mathrm{ZrO}\right)_{2}\right)$ & $<6$ \\
& $\mathrm{Outros} \mathrm{óxidos}_{2}$ & $<1$ \\
\hline PCW & $\mathrm{Al}_{2} \mathrm{O}_{3}$ & 72 a 97 \\
(polycrystalline & $\mathrm{SiO}_{2}$ & 3 a 28 \\
wool) & $\mathrm{Outros} \mathrm{óxidos}_{2}$ & $<0,1$ \\
\hline
\end{tabular}

outro constituinte majoritário é a sílica e óxidos minoritários (alumina, zircônia e titânia) também estão presentes na sua composição (Tabela I); v) PCW - fibras policristalinas feitas pelo homem, contendo percentual de alumina superior a $60 \%$ em massa (Tabela I); vi) mat - lã flexível não agulhada e sem agentes de fixação; vii) manta - mat flexível e agulhado, livre de ligantes e dimensões nominais determinadas; viii) temperatura de classificação - temperatura na qual a retração obtida através do teste de variação linear permanente não excede 4\%; aplicado para mantas, mat, feltros e papéis; não é recomendado utilizar as fibras vítreas continuamente nesta temperatura; as faixas típicas de aplicação das fibras por categoria são: PCW 1800 a $1000{ }^{\circ} \mathrm{C}, \mathrm{FCR} 1400$ a $700{ }^{\circ} \mathrm{C}$ e AES 1200 a $500{ }^{\circ} \mathrm{C}$; ix) resiliência - capacidade de retornar ao valor da dimensão original após ter sido comprimido $50 \%$ em sua espessura.

\section{PROCESSO DE MANUFATURA}

Os processos de manufatura dos isolantes térmicos fibrosos FCR, AES e PCW podem ser divididos entre os métodos de sopro (blowing), centrifugação (spinning) e sol-gel, sendo que os dois primeiros são utilizados para a produção dos produtos vítreos e o último é empregado para os materiais policristalinos. Não se recomenda produzir isolantes fibrosos policristalinos utilizando os dois primeiros métodos, devido ao percentual em massa de alumina presente neste material ser superior a $60 \%$. Este fato faz com que o produto fundido apresente uma baixa viscosidade e uma alta tensão superficial, dificultando a confecção das fibras. Além destes dois fatores, há também o incremento da temperatura de fusão das matérias-primas, tendo como consequência um maior potencial de consumo de energia. Os isolantes térmicos fibrosos AES e FCR são produzidos de acordo com o mesmo processo tecnológico, fusão da matéria-prima em forno elétrico. A diferença básica entre o processo de

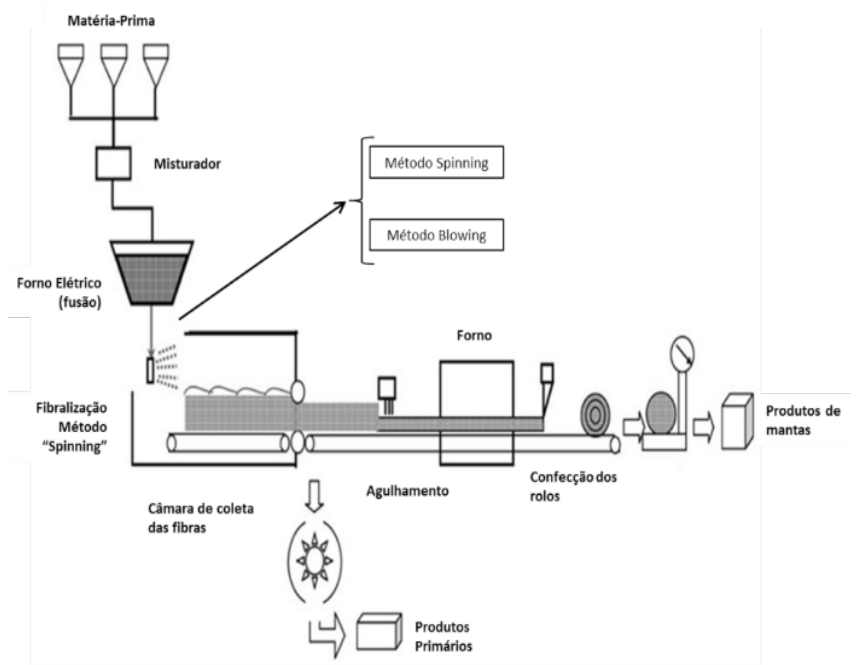

Figura 2: Etapas de fabricação dos isolantes térmicos fibrosos FCR e AES [3].

[Figure 2: Manufacturing steps of the thermal fibrous insulations FCR and AES [3].] 
fabricação está na temperatura de fusão de seus compostos químicos. Para o produto AES, a temperatura de fusão é de aproximadamente $1600{ }^{\circ} \mathrm{C}$. Já para os materiais à base de FCR, este valor chega a aproximadamente $2000^{\circ} \mathrm{C}$ [5]. As etapas de fabricação dos produtos não cristalinos AES e FCR são apresentadas na Fig. 2, sendo que o material fundido pode prosseguir pela metodologia de sopro ou de centrifugação.

Método de sopro (blowing): neste método a produção das fibras é baseada no efeito de arraste pelo fluxo de ar insuflado. O sopro gerado através de uma injeção de ar comprimido ou de vapor separa o material fundido em pequenas gotas, acelerando-as e transformando-as em fibras não ordenadas e com razões variadas entre suas dimensões, comprimento e diâmetro. Geralmente, o valor do diâmetro médio das fibras varia entre 2,5 e 3,5 $\mu \mathrm{m}$. Os métodos convencionais são os de sopro horizontal e sopro paralelo.

Método de centrifugação (spinning): neste método, o material fundido flui para rodas metálicas instaladas abaixo do forno elétrico de fusão das matérias-primas. $\mathrm{O}$ processo de fibralização (formação das fibras) é desempenhado pela rotação em alta velocidade de rodas metálicas dispostas em sequência. A força centrífuga gerada durante o impacto do material fundido nas rodas faz com que este seja separado em pequenas gotas, as quais são transformadas em seguida em fibras não ordenadas e com razões variadas entre suas principais dimensões, comprimento e diâmetro. Geralmente, o valor do diâmetro médio varia entre 3 e $5 \mu \mathrm{m}$.

Nos dois processos apresentados (sopro e centrifugação), pequenos grãos (formato globular ou de meia lua) de vidro
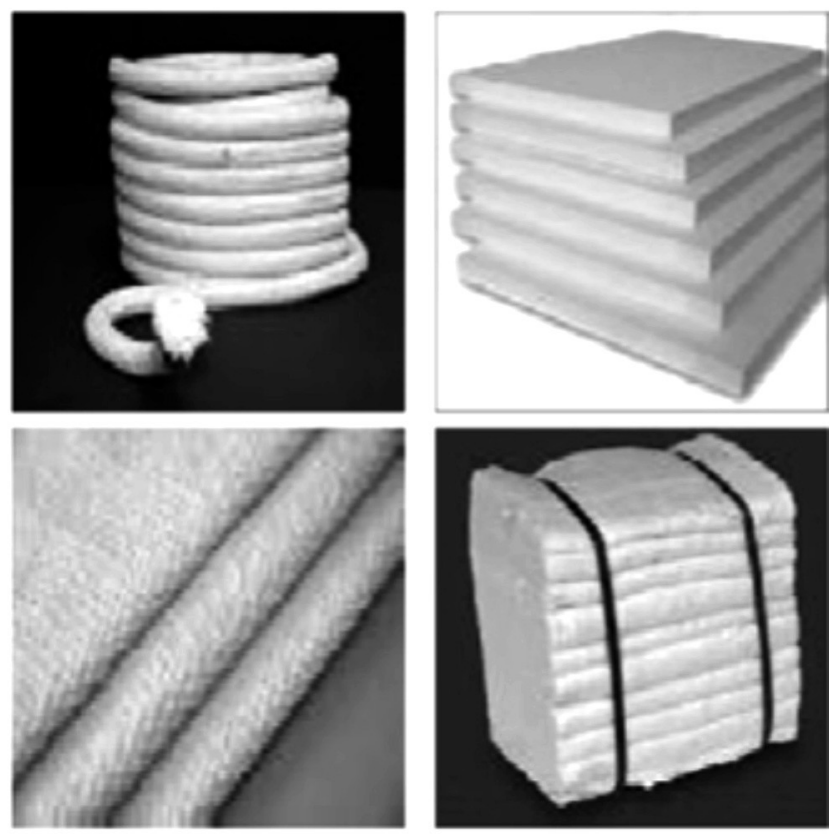

Figura 3: Exemplos de materiais isolantes à base de fibras refratárias [23].

[Figure 3: Insulating material samples using refractory fibers [23].] que não são transformados em fibras, recebem a denominação de shot. Este produto possui um diâmetro médio próximo ou superior a $60 \mu \mathrm{m}$ A presença deste material não fibralizado contribui negativamente na resistência mecânica e no poder de isolamento do produto final [23]. Durante o processo de formação das fibras, alguns shots rompem-se das fibras, sendo então coletados e fundidos novamente. A quantidade de shot no produto final difere significativamente dependendo do fabricante, processo de manufatura e qualidade da matéria-prima. Este item é um fator importante no controle de qualidade. As fibras individuais produzidas durante o processo são direcionadas para uma esteira de malha localizada na câmara de coleta e uma teia de fibras é formada. Esta pode ser embalada como lãs ou processadas como mat. Caso o produto fabricado seja manta, as lãs seguem o fluxo produtivo, passando pelo processo de agulhamento. Este procedimento tem como objetivo fornecer um maior entrelaçamento entre as fibras e consequentemente aumentar a resistência mecânica do produto. Por fim, o material é levado ao forno para a retirada dos ligantes orgânicos. Além destes produtos, outros tipos de materiais também podem ser fabricados, tais como: módulos, peças a vácuo, cordões e tecidos, conforme Fig. 3.

Método sol-gel: genericamente, o processo sol-gel constitui-se na síntese química de óxidos envolvendo sais hidrolisáveis (orgânicos ou inorgânicos) que podem passar pela transição sol-gel. O termo sol é geralmente empregado para definir uma dispersão de partículas coloidais (dimensão entre 1 e $100 \mathrm{~nm}$ ) estável em um fluido, enquanto que o gel pode ser visto como sendo o sistema formado pela estrutura rígida de partículas coloidais (gel coloidal) ou de cadeias poliméricas (gel polimérico) que imobiliza a fase líquida nos seus interstícios [24]. Neste processo são utilizados precursores como alcóxidos metálicos ou sais inorgânicos, que passam por reações de hidrólise e polimerização para formar um sistema coloidal ou sol. O ajuste do $\mathrm{pH}$ do meio e/ou a desidratação deste sistema leva à formação de um gel. Por este processo podem ser obtidos materiais amorfos ou cristalinos, dependendo do precursor, das etapas de fabricação e dos tratamentos térmicos aos quais os materiais são submetidos. Na fabricação dos isolantes térmicos fibrosos policristalinos, os precursores de alumina são soluções aquosas viscosas de sais básicos de alumínio, $\mathrm{AlXn}(\mathrm{OH})_{3-n}$, onde $\mathrm{X}$ pode ser um radical inorgânico $\left(\mathrm{Cl}^{3-}, \mathrm{NO}^{3-}\right)$ ou orgânico $\left(\mathrm{HCOOH}^{-}\right)$. A centrifugação do precursor produz um gel (fibra), o qual é seco e posteriormente aquecido. A decomposição do precursor induz a precipitação de hidróxidos de alumínio, tais como a boemita. Nesta etapa, variações volumétricas e porosidade devem ser cuidadosamente controladas. Acima de $400{ }^{\circ} \mathrm{C}$ e próximo de $1000{ }^{\circ} \mathrm{C}$, a fibra é composta por grãos na faixa de 10 a $100 \mathrm{~nm}$ e de fases de transição da alumina. Acima de $1100{ }^{\circ} \mathrm{C}$, a fase estável $\alpha$-alumina nucleia, ocorrendo um rápido crescimento de seus grãos para dimensões micrométricas, juntamente com a coalescência dos poros. Nesta etapa, as fibras tornam-se bastante frágeis, impossibilitando a sua utilização. Logo, 
para que este material possa ser utilizado, precursores de sílica são adicionados às fibras [25]. O método sol-gel na fabricação de isolantes térmicos fibrosos policristalinos de alumina inclui três etapas principais, a produção do sistema coloidal ou sol, a fibralização (normalmente pelo método do disco giratório) e o tratamento térmico. Esta última etapa é considerada bastante crucial para as características dos produtos, pois influencia diretamente em propriedades importantes, tais como resistência a tração e capacidade de isolamento térmico.

\section{HISTÓRICO DE DESENVOLVIMENTO}

O desenvolvimento das fibras minerais artificiais foi impulsionado por importantes fatores, tais como: desenvolvimento de novas tecnologias de fabricação, disponibilidade de matérias-primas, novas aplicações industriais, temperatura em que cada produto pode ser utilizado continuamente, crises no setor de energia, preocupação com os riscos ocupacionais ocasionados pelo uso da fibra natural asbesto e pela própria utilização do material de FCR. O desenvolvimento destes materiais iniciou-se através da fabricação das fibras cerâmicas refratárias (FCR) na década de 40 , sendo efetivamente comercializadas nas décadas de 50 e 60 nos Estados Unidos e na Europa, respectivamente. A crescente utilização das FCRs como materiais isolantes térmicos foi motivada por dois principais aspectos: comprovação científica que a inalação de fibras de asbesto pode ocasionar sérias patologias, tais como um determinado tipo de câncer conhecido como mesotelioma [26], e o aumento do preço da energia (combustíveis fósseis) na década de 70 [27]. Durante o período compreendido entre as décadas de 40 e 80 , pequenas modificações na formulação das FCRs foram realizadas, por meio de melhorias no processo de manufatura e/ou aumento da disponibilidade de matérias-primas alternativas. Apenas no final da década de 80 e início da década de 90 é que as FCRs sofreram mudanças significativas na composição química das fibras e/ou a metodologia de fabricação, desenvolvendo outros produtos. As fibras PCW foram inventadas nos anos 70, mas a sua comercialização iniciou-se no final da década de 90. Nesta década iniciou-se a fabricação das fibras AES, objetivando melhorar principalmente a sua solubilidade nos sistemas biológicos, mais comumente conhecida como biopersistência.

Dentre o processo evolutivo das FCRs, estas foram desenvolvidas conforme suas temperaturas de classificação, iniciando pelas fibras para $1260{ }^{\circ} \mathrm{C}$, passando pelas fibras para $1400{ }^{\circ} \mathrm{C}$ (aumento no teor de alumina, seguido da adição de $\mathrm{ZrO}_{2}$ ) e, por fim, as fibras para $1500{ }^{\circ} \mathrm{C}$ (adição de $\mathrm{Cr}_{2} \mathrm{O}_{3}$ ). A fibra cerâmica refratária na classe de $1260{ }^{\circ} \mathrm{C}$ consiste em produtos com $47-51 \%$ em massa de $\mathrm{Al}_{2} \mathrm{O}_{3}$ e 49 $53 \%$ em massa de $\mathrm{SiO}_{2}$, aproximadamente. A razão entre os compostos alumina/sílica dentro das faixas apresentadas gera pequena influência na propriedade de refratariedade. Contudo, características como diâmetro das fibras, quantidade de shot, área superficial específica das fibras, dentre outras, influenciam diretamente em propriedades importantes, tais como resistência mecânica e isolamento térmico. Para as FCRs da classe de $1400{ }^{\circ} \mathrm{C}$, foram desenvolvidos dois tipos de materiais: no primeiro aumentou-se a porcentagem de alumina para 56-60\% em massa (a faixa da sílica é de 40$44 \%$ em massa); e no segundo material, foi acrescentada a fase $\mathrm{ZrO}_{2}<20 \%$ em massa, além da presença dos óxidos $\mathrm{Al}_{2} \mathrm{O}_{3}<37 \%$ e $\mathrm{SiO}_{2}>48 \%$ (percentuais em massa). Por fim, as FCRs da classe de $1500{ }^{\circ} \mathrm{C}$ foram desenvolvidas objetivando reduzir o efeito de degradação das fibras, após exposição aos fatores temperatura e tempo; contudo, os resultados esperados não foram alcançados. Outro fator agravante é o risco ambiental. Caso ocorra uma reação de oxirredução do $\mathrm{Cr}$ (III) - cromo trivalente, para Cr (VI) - cromo hexavalente, o material pode ser classificado como patogênico à espécie humana.

Para as fibras AES, a sua invenção foi datada nos anos 80 e a sua comercialização iniciou-se, principalmente na Europa, com maior expressão na década de 90 [20]. Este fato ocorreu devido às fibras cerâmicas refratárias (RCF) serem classificadas como substâncias possivelmente patogênicas à espécie humana $[17,18]$. As fibras AES apresentam em sua composição química típica percentuais em massa, de sílica entre 50-82\% e de óxidos de metais alcalinos terrosos ( $\mathrm{CaO}$ e $\mathrm{MgO}$ ) compreendidos em 18-43\%. Em processo de comercialização, existem duas classes de fibras AES, sendo que a primeira apresenta $60-70 \%$ em $\mathrm{SiO}_{2}$ e $25-40 \%$ em $\mathrm{CaO}$ e $\mathrm{MgO}$ e a segunda possui 70-80\% em $\mathrm{SiO}_{2}$ e 18 $25 \%$ em $\mathrm{CaO}$ e $\mathrm{MgO}$. Uma das principais diferenças entre os dois materiais é a temperatura de classificação, sendo que o material da primeira classe apresenta o valor de $1200{ }^{\circ} \mathrm{C}$ e as fibras da segunda classe apresentam o valor de $1300^{\circ} \mathrm{C}$. As fibras policristalinas (PCW) foram inventadas nos anos 70 [28]. Geralmente, fabricam-se três tipos de materiais, sendo o primeiro composto de aproximadamente $72 \%$ de alumina e $28 \%$ de sílica, contendo a fase mulita $\left(3 \mathrm{Al}_{2} \mathrm{O}_{3} \cdot 2 \mathrm{SiO}_{2}\right)$ como constituinte majoritário, o segundo formado por aproximadamente $95 \%$ de alumina e $5 \%$ de sílica, contendo a fase $\alpha$-alumina como principal constituinte, e o último tipo contendo aproximadamente $80 \%$ de alumina e $20 \%$ de sílica, contendo ambas as fases $\alpha$-alumina e mulita na sua composição química. O primeiro material é classificado como fibra de mulita e os dois últimos são denominados por fibras de alumina. Todos os percentuais apresentados estão em massa.

\section{APLICAÇÕES NA INDÚSTRIA SIDERÚRGICA}

Objetivando apresentar as aplicações das fibras FCR, AES e PCW na indústria siderúrgica de uma forma mais detalhada, optou-se por dividir as unidades produtivas em cinco grandes áreas, destacando-se importantes equipamentos de cada região: preparação da carga (coqueria), redução (alto forno, sistema de injeção de ar e carro torpedo), refino (panela de aço e tampa de aquecedor de panela de aço), lingotamento (distribuidor e tampa de aquecedor do distribuidor) e laminação (fornos de aquecimento, reaquecimento e tratamento térmico), conforme Fig. 4. 


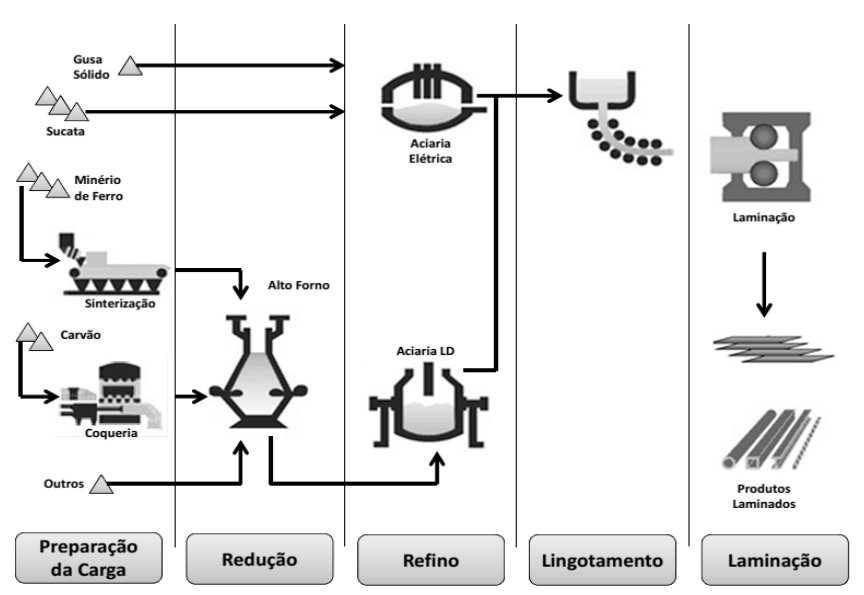

Figura 4: Desenho esquemático da produção de aço [29]. [Figure 4: Flowchart of the steel production [29].]

Preparação da carga (coqueria): a coqueria é a unidade industrial que transforma a mistura de carvões minerais em coque. O coque metalúrgico é empregado nos altos fornos, onde pode atuar como combustível, redutor, fornecedor de carbono ao gusa e permeabilizador da carga. Uma bateria de fornos de coque com recuperação de subprodutos é constituída de fornos verticais geralmente de 11 a $15 \mathrm{~m}$ de comprimento, 3 a $7 \mathrm{~m}$ de altura e 300 a $550 \mathrm{~mm}$ de largura. Suas paredes são construídas de tijolo refratário. Durante o processo, a mistura de carvões é aquecida a $1100{ }^{\circ} \mathrm{C}$, e o tempo de coqueificação varia, geralmente, de 16 a $18 \mathrm{~h}$. Uma vez que o coque atingiu o grau máximo de transformação, este é desenfornado pelas portas. Estas portas são abertas para que o material seja retirado e uma nova batelada de carvão é inserida no forno. Logo, como o revestimento refratário das portas é exposto ao gradiente de temperatura (choque térmico) de aproximadamente $1000{ }^{\circ} \mathrm{C}$, os materiais geralmente utilizados nestas regiões são as fibras FCR, AES e PCW.

Redução (alto forno, canal de corrida e carro torpedo): o alto forno é um tipo de forno de cuba empregado na produção de ferro gusa, pela fusão redutora de minérios de ferro em presença de carvão vegetal ou coque e fundentes. Estas matérias-primas são carregadas pelo topo e, na descida, são transformados pela ação dos gases ascendentes, provenientes da combustão do carvão ou coque com o ar quente (oxigênio), soprado pelo sistema de injeção de ar. Os produtos principais da redução são escória e ferro gusa líquidos, os quais são retirados pelo cadinho (parte inferior do equipamento) através do furo de corrida. Estes dois produtos são vazados no canal de corrida, sendo que o gusa é direcionado ao carro torpedo e a escória segue para o sistema de granulação. Geralmente os revestimentos isolantes permanentes utilizados tanto na região do sistema de injeção de ar, quanto no canal de corrida e no carro torpedo são compostos por fibras FCR, AES e PCW.

Refino (panela de aço e tampa de aquecedor de panela de aço): o processo de produção de aço em uma aciaria pode ser dividido em duas etapas, refino primário e secundário. Na primeira etapa acontece o refino do ferrogusa. Esta consiste no carregamento de sucata sólida e gusa líquido no convertedor $\mathrm{LD}$ e posterior sopro de oxigênio no banho. Durante o sopro, elementos como carbono, silício, manganês e fósforo são oxidados. Antes do término da fase de sopro de oxigênio e posterior vazamento do aço nas panelas, estas últimas são aquecidas através de uma estação de aquecimento de panelas de aço, composta por uma tampa com queimador, contendo como revestimento de trabalho as fibras FCR ou PCW. Finalizada a fase de sopro, o aço é então vazado nas panelas, já aquecidas, seguindo para o refino secundário. Esta etapa consiste no ajuste fino de composição química, geralmente em atmosfera redutora, e acerto de temperatura. Geralmente um dos produtos isolantes utilizado como revestimento permanente nas panelas é a fibra FCR ou AES.

Lingotamento (distribuidor e tampa de aquecedor do distribuidor): no processo de lingotamento contínuo, o aço líquido é transferido para uma calha de distribuição (distribuidor) pelo fundo em panelas convencionais. O distribuidor serve para manter um volume de aço líquido, objetivando alimentar o molde com uma pressão ferrostática constante e controlar a vazão do aço para o molde. O molde (lingoteira) é fabricado de cobre ou grafite, e tem um movimento oscilatório para reduzir a aderência do aço em suas paredes; além disto, utilizam-se lubrificantes à base de óleo ou grafite. Anterior à transferência do aço líquido para o distribuidor, este último é aquecido através de uma estação de aquecimento composta por uma tampa com queimador, sendo que esta tampa é revestida geralmente por fibras FCR ou PCW.

Laminação (fornos de aquecimento, reaquecimento e tratamento térmico): a laminação é um processo de conformação mecânica no qual o material é forçado a passar entre dois cilindros, girando em sentidos opostos, com praticamente a mesma velocidade superficial e separados entre si de uma distância menor que o valor da espessura inicial do material a ser deformado. Esta pode ser a quente ou a frio. No caso em que há temperatura envolvida no processo, fornos de reaquecimento são utilizados para tornar os produtos semiacabados (tarugos ou placas) suficientemente plásticos, para permitir a redução mecânica à secção desejada. Os fornos de aquecimento são usados para tornar produtos semiacabados (ex., lupas) em produtos acabados (ex., tubos). Já os fornos de tratamento térmico são empregados no aquecimento de produtos acabados (ex., tubos) a temperaturas em que algumas microestruturas e propriedades finais são desejadas. Para fornos de aquecimento, em que a máxima temperatura de trabalho é de $1050{ }^{\circ} \mathrm{C}$, as fibras FCR e AES podem ser utilizadas como juntas de expansão e/ou como revestimento isolante permanente e/ou como revestimento de trabalho.

\section{VANTAGENS AMBIENTAL E ECONÔMICA DE SEUS USOS FRENTE ÀS COMPOSIÇÕES DE MATERIAIS REFRATÁRIOS COMERCIALMENTE EMPREGADOS NA INDÚSTRIA}

Dependendo de sua aplicação, cada material refratário 
irá apresentar vantagens e desvantagens tecnológicas, ambientais e econômicas. Principalmente durante as etapas de investimento e de otimização das instalações industriais, critérios econômicos e aspectos ambientais são cada vez mais decisivos e colocados nas pautas de discussão, uma vez que várias leis, diretivas e políticas exigem melhorias relacionadas a estes dois fatores. Algumas empresas por serem filiais de unidades europeias são obrigadas a cumprir grande parte das regulamentações ambientais e econômicas exigidas pelo mercado europeu. Dentre estas exigências destaca-se o plano da comissão europeia "Europa 2020". Este plano possui como uma de suas estratégias garantir que as seguintes metas sejam alcançadas até o ano de 2020: redução em $20 \%$ de emissões de gases de efeito de estufa relativas aos níveis de 1990, ou em 30\%, se as condições permitirem; incremento em $20 \%$ da quota de utilização de energias renováveis no consumo final energético; e incremento de 20\% em eficiência energética [30]. Desta forma, parâmetros econômicos e ambientais relevantes, tais como consumo de energia, aumento de produtividade e, especialmente, redução de emissão de gases responsáveis pelo efeito estufa, merecem destaque e são aqui apresentados, objetivando demonstrar importantes vantagens da utilização dos materiais isolantes FCR, AES e PCW nas instalações industriais.

Na Fig. 5 encontram-se representadas três composições de construções de revestimentos refratários utilizadas em paredes de fornos industriais. Estas composições foram comparadas visando avaliar as vantagens tecnológicas, econômicas e ambientais das lãs isolantes para alta temperatura (HTIW) frente aos outros dois tipos de revestimentos comumente usados, compostos por tijolos e/ou concretos da classe de materiais aluminosos e silicoaluminosos. Os diferentes cones indicados na Fig. 5 e posicionados abaixo de cada formato de revestimento de parede simbolizam a menor quantidade de massa, matéria-prima e energia armazenada e consequentemente menor consumo de energia e menor emissão de $\mathrm{CO}_{2}$ para a composição 3, quando comparada aos outros dois arranjos [31]. É interessante relatar que estes três tipos de construções são bastante utilizados na indústria siderúrgica, principalmente em fornos de aquecimento, reaquecimento e tratamento térmico (têmpera e revenimento). Porém, cabe salientar que uma nova geração de materiais refratários com capacidade de isolamento térmico igual ou superior aos revestimentos HTIW já se encontram em processo de comercialização [32]. Além da própria avaliação tecnológica, econômica e ambiental apresentada na Fig. 5 , outros benefícios construtivos também podem ser mencionados, tais como: a menor quantidade de massa do revestimento HTIW permite uma construção metálica do forno menos robusta e consequentemente a fundação é projetada para suportar menor carga (menos aço e concreto). Adicionalmente, devido à baixa densidade do material, o manuseio e a instalação tornam-se mais simples e ágil. Por fim, após a montagem, o forno necessita de um menor tempo de aquecimento e encharque, devido a estes materiais

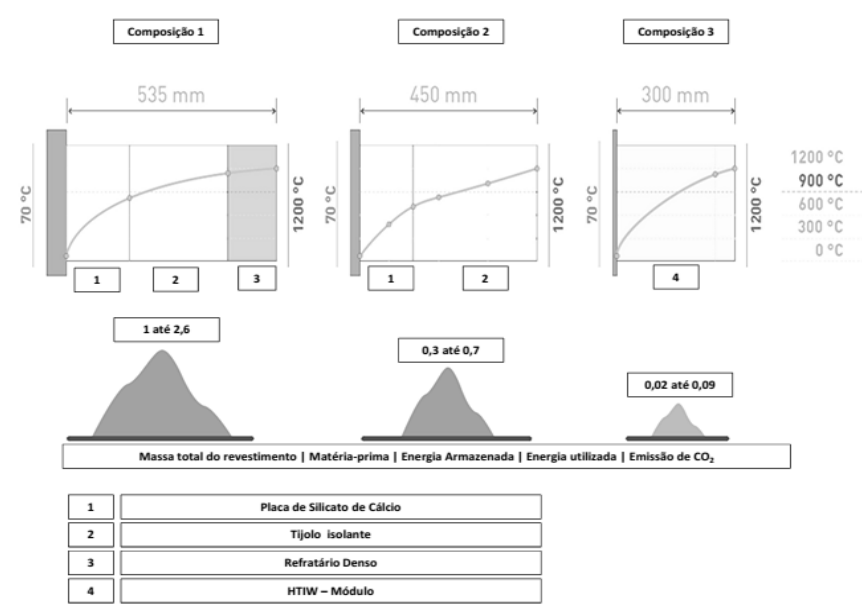

Figura 5: Composições usuais de revestimento refratários empregados em fornos industriais [31].

[Figure 5: Common refractory linings used in furnaces [31].]

não necessitarem de uma secagem prévia e possuírem baixa inércia térmica em relação aos demais refratários.

$\mathrm{Na}$ Tabela II encontram-se dados comparativos, nas categorias econômica e ambiental, entre diferentes tipos de revestimentos refratários instalados em um forno de forja [2]. Foram utilizadas três modalidades construtivas, sendo a primeira apenas com material denso, a segunda apenas com material isolante e a última apenas com as FCR. Esses equipamentos apresentavam as seguintes características: funcionamento intermitente, gás natural como combustível, 48 ciclos de tratamento térmico por ano, $4700 \mathrm{~h}$ em operação por ano, período da avaliação de 5 anos, temperatura de trabalho de $1300{ }^{\circ} \mathrm{C}, 212 \mathrm{~m}^{2}$ de área de revestimento e custo de gás natural de $0,17 € / \mathrm{m}^{3}$. Uma vez que não havia informações relativas à espessura dos revestimentos, bem como de suas especificações precisas, foi utilizado o seguinte critério para avaliar a Tabela II, a temperatura de face fria esperada foi a mesma para as três configurações de modalidade construtiva. No quesito econômico, o revestimento contendo FCR apresentou um armazenamento de energia 18 vezes menor quando comparado ao refratário denso e 7 vezes menor quando correlacionado ao material isolante. Este fator é de grande importância quando se realiza uma avaliação de um processo intermitente, pois toda vez que o forno é resfriado e posteriormente aquecido o revestimento que possui menor capacidade de armazenamento de energia necessita menor quantidade de calor, gerada pela queima do combustível, para garantir o seu completo encharque. Avaliando o aspecto ambiental, pôde-se concluir que: como o consumo de energia é minimizado por uma menor demanda de gás natural necessária para encharcar o revestimento do forno em FCR, uma menor emissão de $\mathrm{CO}_{2}$ também é esperada.

Na Tabela III encontram-se alguns importantes dados de dois fornos de reaquecimento da empresa Sumitomo Metal Corporation. De acordo com a empresa, a economia global de energia foi de $13 \%$ após instalação dos revestimentos em fibras cerâmicas nas regiões do teto, parede e vigas e colunas móveis e fixas (também conhecidas como skids). 
Tabela II - Comparação entre três revestimentos de um forno de forja [2]. [Table II - Comparison between three linings of a forging furnace [2].]

\begin{tabular}{ccccc}
\hline Revestimento do forno & & Refratário denso & Refratário isolante & FCR \\
\hline Energia específica armazenada & $\mathrm{MJ} / \mathrm{m}^{2}$ & 817,82 & 330,35 & 45,33 \\
Custos operacionais (apenas energia) & $€ / \mathrm{m}^{2} / \mathrm{a}$ & 414,27 & 214,22 & 121,04 \\
Custos totais & $€ / \mathrm{m}^{2} / \mathrm{a}$ & 502,96 & 292,52 & 179,59 \\
Consumo de energia + emissão de $\mathrm{CO}_{2}$ & $\%$ & 70 & 58 & Base \\
\hline
\end{tabular}

Tabela III - Dados de dois fornos de vigas caminhantes da empresa Sumitomo Metal. [Table III - Data of two walking beam furnaces from Sumitomo Metal Corporation.]

\begin{tabular}{ccc}
\hline & Forno 1 & Forno 2 \\
\hline Tipo & Vigas caminhantes (8 zonas) & Vigas caminhantes (6 zonas) \\
Dimensão $(\mathrm{m})$ & 55 (comprimento) $\mathrm{x} 12,7$ (largura) & 31 (comprimento) $\times 12,7$ (largura) \\
Capacidade $(\mathrm{t} / \mathrm{h})$ & $450\left(25^{\circ} \mathrm{C} \rightarrow 1270{ }^{\circ} \mathrm{C}\right)$ & $225\left(25^{\circ} \mathrm{C} \rightarrow 1270{ }^{\circ} \mathrm{C}\right)$ \\
Combustível $(\mathrm{PCI})$ & $\mathrm{COG}\left(\right.$ gás de coqueria) $=19,3 \mathrm{MJ} / \mathrm{Nm}^{3}$ \\
Refratário & Teto, parede e skids: módulos de fibra cerâmica; soleira: refratário \\
FCR (principal utilização) & Espessura de teto e parede $=350 \mathrm{~mm}$, coluna dos skids $=100 \mathrm{~mm}$ e viga dos skids $=80 \mathrm{~mm}$ \\
\hline
\end{tabular}

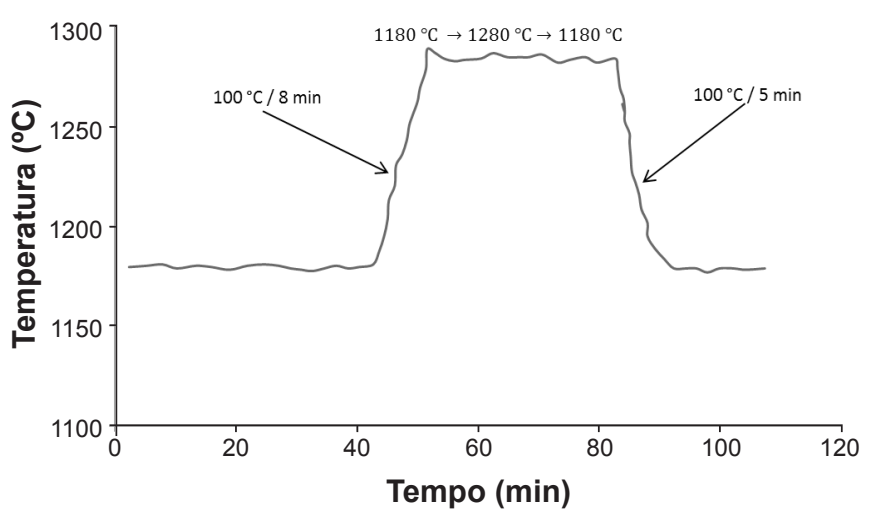

Figura 6: Resposta da inércia térmica do forno 1 da empresa Sumitomo Metal Corporation.

[Figure 6: Thermal inertia response of furnace number 1 from Sumitomo Metal Corporation.]

Do total, $5 \%$ das economias foram atribuídos à melhoria de isolamento do novo revestimento e $8 \%$ foram intensificados pela metodologia de operação do forno, particularmente mais eficaz para a zona de pré-aquecimento. Esta nova concepção de revestimento permitiu a prática de se trabalhar com uma combinação de carga fria e quente. Avaliando o forno 1 da empresa, conforme Fig. 6, um incremento na temperatura da zona de aquecimento de $100{ }^{\circ} \mathrm{C}$, ou seja, de 1180 para $1280{ }^{\circ} \mathrm{C}$, foi alcançado em um período de 8 min. Outro ponto observado é que à medida que as placas de aço foram desenfornadas a aproximadamente $5 \mathrm{~m}$ de distância da zona de aquecimento, um decréscimo de $100{ }^{\circ} \mathrm{C}$ foi alcançado em um intervalo de $5 \mathrm{~min}$. Esta baixa inércia térmica é bastante demandada nas indústrias, em especial nos fornos de austenitização e revenimento, uma vez que rápidas variações nas temperaturas das zonas destes equipamentos são solicitadas, principalmente quando se trabalha com produtos que demandam diferentes temperaturas de tratamento térmico. De acordo com os dados da curva de resfriamento da zona de encharque do forno 2 da empresa, foi observado que o resfriamento do equipamento de 1250 a $100{ }^{\circ} \mathrm{C}$ foi alcançado em aproximadamente $7 \mathrm{~h}$, sendo que para a concepção antiga do revestimento em tijolos densos e isolantes esta atividade levava aproximadamente $48 \mathrm{~h}$. Uma hora após o desligamento dos queimadores, a água de refrigeração das vigas e colunas fixas e móveis, skids, é drenada e $6 \mathrm{~h}$ após esta atividade as portas laterais para a manutenção são abertas. A possibilidade de um resfriamento e um aquecimento mais rápido, desde que não ocasione danos por choque térmico significativos no material refratário, aumenta a disponibilidade e consequentemente a produtividade de uma planta industrial. Esta característica torna as fibras isolantes efetivas para o cumprimento desta exigência.

A corporação N.S.C. (Nippon Steel Corporation) também reportou sobre a baixa inércia térmica do revestimento em fibra cerâmica do forno de reaquecimento de placas em Kimitsu Works [3]. Foram comparadas duas modalidades construtivas, uma com revestimento refratário convencional (tijolos densos e isolantes) e outra em fibra cerâmica. $\mathrm{O}$ forno com a primeira configuração apresentou uma inércia térmica de $1{ }^{\circ} \mathrm{C} / \mathrm{min}$, contra $7{ }^{\circ} \mathrm{C} / \mathrm{min}$ para o revestimento majoritário em fibra cerâmica. Estes dados foram levantados durante a etapa de resfriamento, partindo da temperatura inicial igual a $1270{ }^{\circ} \mathrm{C}$ e reduzindo para 1200 ${ }^{\circ} \mathrm{C}$. Esta característica de baixa absorção térmica das fibras isolantes é observada devido a estas apresentarem baixo valor de densidade aparente quando comparadas a outros tipos de revestimentos. Enquanto as fibras PCW, utilizadas 
em temperatura constante de $1500{ }^{\circ} \mathrm{C}$, possuem valor de densidade aparente próximo a $100 \mathrm{~kg} / \mathrm{m}^{3}$, tijolos isolantes que podem ser expostos à mesma temperatura de trabalho, sem perda de suas propriedades, possuem valores próximos a $1000 \mathrm{~kg} / \mathrm{m}^{3}$ [33]. Logo, estes tijolos isolantes possuem 10 vezes a mais de massa a ser aquecida, quando comparados às fibras refratárias isolantes.

$\mathrm{Na}$ Fig. 7 encontram-se representados cinco tipos construtivos de isolamentos térmicos utilizados nos carros de carregamento de fornos túneis. Estes equipamentos são empregados na queima de peças cerâmicas (refratários e porcelanas) [23]. Objetivando comparar estas cinco modalidades de construção de carros de carregamento para fornos túneis, foram avaliadas as perdas energéticas através dos revestimentos durante o ciclo de queima. O tempo necessário para atingir a máxima temperatura de queima $\left(1300{ }^{\circ} \mathrm{C}\right.$ ) foi de $13,5 \mathrm{~h}$. A carga permaneceu durante $4 \mathrm{~h}$ na zona de encharque na temperatura de $1300{ }^{\circ} \mathrm{C}$, sendo resfriada internamente a $300{ }^{\circ} \mathrm{C}$ em $8,5 \mathrm{~h}$ e retirada do forno após $10 \mathrm{~h}$ ao alcançar a temperatura de $150^{\circ} \mathrm{C}$. As dimensões do carro foram iguais a $1500 \mathrm{~mm}$ de largura, $2000 \mathrm{~mm}$ de altura e $400 \mathrm{~mm}$ de comprimento. As temperaturas foram registradas no topo do carro. O tempo total do ciclo foi de $36 \mathrm{~h}$. As perdas de energia $\left(\mathrm{kcal} / \mathrm{m}^{2}\right)$ de todas as cinco construções após 17,5 h de tratamento foram de 153000 (A), 148000 (B), 98000 (C), 92000 (D) e 65000 (E), ou seja, comparando a construção A que não possuía nenhum material em fibra e a construção E que continha quase $100 \%$ de fibra isolante, as perdas energéticas através do carro A em relação ao E foram praticamente 2,4 vezes maiores. Nenhum outro fator foi avaliado neste estudo.

Cabe ressaltar que outros pesquisadores também conduziram experimentos em carros de carregamento de fornos túneis. Em um estudo [34], foram comparados dois tipos de revestimentos: umem fibra isolante e outrocomposto por uma nova geração de materiais refratários microporosos. Foram instalados nove termopares em diferentes pontos

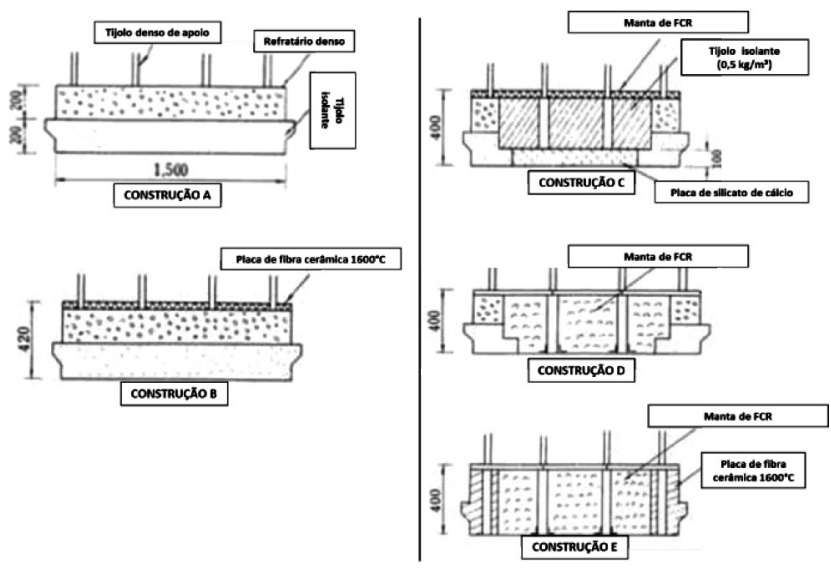

Figura 7: Tipos de construções de carros de carregamento de fornos túneis [23].

[Figure 7: Different types of refractory linings in tunnel furnaces [23].] na espessura dos dois modelos de revestimentos do carro. Todo o ciclo de queima foi monitorado. Os resultados obtidos, em relação à característica de isolamento térmico, demonstraram que o material microporoso apresentou melhor comportamento em relação às fibras avaliadas [34].

Apesar de todas as vantagens apresentadas em relação às fibras isolantes, é importante salientar que características ligadas à atmosfera dos equipamentos, bem como aos aspectos de saúde e segurança, também devem ser avaliadas na escolha do revestimento refratário. Os materiais FCR e AES são aplicáveis em atmosferas neutras e oxidantes, sendo que em atmosferas redutoras pode ocorrer um decréscimo da sua vida útil [1]. Uma das explicações está ligada à possível reação do carbono, proveniente da atmosfera $(\mathrm{CO})$, com a sílica, em temperaturas próximas a $1000{ }^{\circ} \mathrm{C}$, conforme reações químicas descritas pelas Equações A e B [35]. Estas duas reações podem ser catalisadas, caso seja constatada a presença do elemento químico ferro $(\mathrm{Fe})$ na microestrutura dos materiais.

$$
\begin{aligned}
& \mathrm{SiO}_{2}+3 \mathrm{C} \rightarrow \mathrm{SiC}+2 \mathrm{CO} \\
& 2 \mathrm{SiO}_{2}+\mathrm{SiC} \rightarrow 3 \mathrm{SiO}+\mathrm{CO}
\end{aligned}
$$

Outra possível degradação do revestimento ocasionada por atmosferas redutoras pode ser atribuída à presença de $\mathrm{H}_{2}$. Em temperaturas superiores a $1200{ }^{\circ} \mathrm{C}$, óxidos de baixa estabilidade, tais como $\mathrm{SiO}_{2}$ (nas fases tridimita, cristobalita ou na forma de silicato), reagem com o $\mathrm{H}_{2}$, conforme reação representada pela Equação C [36]. A redução da sílica fragiliza a microestrutura do refratário, diminuindo a sua resistência mecânica e ocasionando falhas prematuras no revestimento.

$$
\mathrm{SiO}_{2}(\mathrm{~s})+\mathrm{H}_{2}(\mathrm{~g}) \rightarrow \mathrm{SiO}(\mathrm{g})+\mathrm{H}_{2} \mathrm{O}(\mathrm{g})
$$

Já para atmosferas onde há presença de umidade e/ou condensado (vapor de água), as fibras FCR são aplicáveis e as fibras AES não são recomendadas [1]. Esta diferença pode ser explicada considerando a composição química destes materiais. As fibras AES possuem em sua constituição óxidos de metais alcalinos e alcalinos terrosos (percentual em massa superior a 18\%). Estes componentes exercem efeito sobre a solubilidade da sílica em água, tornando as fibras menos estáveis para este tipo de aplicação [37]. Este efeito pode ser explicado através de três etapas. A primeira fase refere-se à penetração do íon $\mathrm{H}^{+}$, proveniente da molécula de água, na microestrutura da fibra. Este íon $\left(\mathrm{H}^{+}\right)$substitui um íon de um dos óxidos alcalinos, e este último fica em solução. $\mathrm{O}$ oxigênio não ligado faz uma união com o íon $\mathrm{H}^{+}$. $\mathrm{Na}$ segunda etapa, o íon $\mathrm{OH}^{-}$da água destrói a ligação $\mathrm{Si}$ $\mathrm{O}-\mathrm{Si}$, formando oxigênios não ligados. Na última e terceira fase, os oxigênios não ligados reagem com as moléculas de água, formando outro oxigênio não ligado, íons de $\mathrm{H}^{+}$e $\mathrm{OH}^{-}$. Este último íon gerado repete a reação da segunda etapa. $\mathrm{O}$ ácido silícico $\left(\mathrm{H}_{2} \mathrm{SiO}_{4}\right)$ então formado é solúvel em água em 
condições favoráveis ( $\mathrm{pH}$, temperatura, concentração de íon e tempo) [35].

Em relação a solicitações físicas, os produtos FCR e AES no formato de manta não devem ser utilizados como revestimento de trabalho, caso a velocidade dos gases seja superior a $12 \mathrm{~m} / \mathrm{s}$ [38]. Este fato é explicado devido aos baixos valores de suas resistências mecânicas, geralmente na faixa de algumas dezenas de $\mathrm{kPa}$ [4]. Em relação aos riscos ocupacionais, podem-se destacar dois pontos de atenção: o manuseio das FCR como recebidas e o manuseio das fibras vítreas (ex., FCR e AES) após exposição a altas temperaturas $\left(>900{ }^{\circ} \mathrm{C}\right)$ e por determinados períodos de tempo ( $>24 \mathrm{~h}$ ). Como este último assunto apresenta grande notoriedade nos meios científico e industrial, um tópico com considerações relevantes mereceu ser inserido neste trabalho, e é apresentado na próxima seção relacionada aos problemas ocupacionais.

\section{PROBLEMAS OCUPACIONAIS RELACIONADOS À SUA UTILIZAÇÃO}

Este tópico é dividido em três itens, sendo que na primeira parte são discutidos conceitos em relação às fibras ditas respiráveis e parâmetros importantes que influenciam diretamente no seu grau de toxicidade. Na segunda parte, informações a respeito de rotas usuais de administração das fibras em ensaios laboratoriais são julgadas e, por fim, o último item é reservado às classificações vinculadas aos riscos ocupacionais das três categorias de materiais estudadas neste documento.

\section{Principais características toxicológicas das fibras}

Fibras consideradas respiráveis são aquelas que podem alcançar e se depositar nos alvéolos pulmonares. A Organização Mundial de Saúde (OMS) considera fibra respirável como uma partícula com diâmetro menor do que $3 \mu \mathrm{m}$ e comprimento maior do que $5 \mu \mathrm{m}$, além de ter razão superior a 3 entre as dimensões comprimento e diâmetro. Além disso, a OMS avalia as fibras como sendo respiráveis por seres humanos, quando estas apresentam um diâmetro aerodinâmico médio próximo ou menor a $3,5 \mu \mathrm{m}$ e comprimento menor que $200 \mu \mathrm{m}$ [39]. Define-se diâmetro aerodinâmico como sendo o diâmetro de uma esfera com a densidade de $1 \mathrm{~g} / \mathrm{cm}^{3}$ e tendo a mesma velocidade terminal de sedimentação do que a partícula, que neste caso é a própria fibra. Este conceito equivalente é comumente utilizado para se definir esta dimensão, pois este se adapta com a capacidade de penetração e probabilidade de deposição das partículas no sistema respiratório. Quando fibras respiráveis naturais ou artificiais (FCR, AES ou PCW) são inaladas, há duas prováveis consequências: estas podem ser expelidas ou retidas nos pulmões. Para que o acúmulo das fibras nos pulmões possa ocasionar complicações patológicas, considerações relativas aos seus mecanismos toxicológicos necessitam de uma prévia avaliação. Dentre os diversos parâmetros que influenciam diretamente o grau de toxicidade das fibras, três merecem destaque: dimensão (comprimento e diâmetro), dosagem (exposição cumulativa) e durabilidade (habilidade da fibra de persistir no tecido pulmonar, conhecida como biopersistência). Estes fatores são conhecidos como "os três Ds" [40]. Para avaliar as características toxicológicas das fibras, não se aconselha estudar apenas um fator isolado. Esta análise deve ser conduzida objetivando correlacionar todos os fatores, pois modificações em qualquer parâmetro podem trazer alterações e influenciar nos resultados de toxicidade do material avaliado.

$\mathrm{O}$ tópico dimensão, especificamente em relação à espécie humana, pode ser vinculado a dois aspectos: o depósito e a remoção das fibras dos alvéolos pulmonares. Avaliando o primeiro aspecto, as fibras que não guardam a relação da OMS são ditas não respiráveis e, em consequência, a probabilidade de ocorrer uma retenção é baixa. A sedimentação pulmonar é percebida de uma melhor forma para diâmetros e comprimentos próximos a 1 e $8 \mu \mathrm{m}$, respectivamente. Já para o aspecto de remoção, fibras que possuem um comprimento inferior ao diâmetro dos macrófagos, que é de $15 \mu \mathrm{m}$, são fagocitadas e removidas por transporte via sistema mucociliar ou gânglios linfáticos locais (processo fisiológico), e/ ou dissolvidas por fluidos biológicos (processo físicoquímico). Fibras com comprimento maior que $15 \mu \mathrm{m}$ são parcialmente fagocitadas pelos macrófagos alveolares e/ ou podem ser parcialmente dissolvidas por processos físico-químicos. [7]. Logo, avaliando-se apenas o critério dimensão isoladamente, pode-se estimar que fibras de mesmo diâmetro, porém com maiores comprimentos, podem apresentar tendência em permanecer na região pulmonar por mais tempo, antes de serem parcialmente ou totalmente removidas. Esta conclusão está ancorada em outros trabalhos [41, 42]. Nestas pesquisas, as fibras longas (comprimento $>20 \mu \mathrm{m}$ ) foram consideradas potencialmente mais patogênicas quando comparadas às fibras mais curtas [41, 42].

A biopersistência pode ser definida como "a retenção de fibras no pulmão, em função do tempo, considerando a quantidade, as dimensões, a área superficial específica, a estrutura superficial e química, a composição química e características similares. Mudanças em qualquer parâmetro podem alterar a toxicidade das fibras". A durabilidade é medida pela quantidade de tempo que a fibra leva para fragmentar mecanicamente em partículas menores ou ser dissolvida pelos fluidos biológicos [43]. Para o tópico dosagem, esta é definida pela concentração de fibras, expressa pela quantidade em relação ao tempo, que é inalada e posteriormente depositada nos pulmões. De acordo com o valor da concentração, este pode ocasionar sobrecarga pulmonar, que é uma condição onde partículas de baixa solubilidade depositadas nos pulmões reduzem a ação de remoção destes materiais através dos processos fisiológicos e físico-químicos e, como consequência, podem ocasionar complicações, como por exemplo inflamações [44]. 


\author{
Rotas de administração das fibras em testes \\ laboratoriais
}

O grau de patogenicidade das fibras frente a animais de laboratório, ex. ratos, geralmente é estudado através de diferentes rotas de administração, ex. inalação nasal, instilação intratraqueal, injeção pleural e injeção peritoneal. Cada uma apresenta vantagens e desvantagens e, de fato, não há concordância geral sobre qual rota melhor prediz o risco de desenvolver câncer em seres humanos [7]. A rota de administração das fibras por inalação nasal apresenta algumas críticas. A quantidade de material utilizada geralmente é superior em relação aos outros métodos citados, uma vez que se deve garantir que as fibras alcancem os órgãos avaliados, antes de serem removidas pelos processos fisiológicos e/ou físico-químicos do organismo. $\mathrm{O}$ teste requer equipamentos específicos e caros. Torna-se difícil obter reprodutibilidade dos dados, uma vez que não se pode garantir que as mesmas quantidades de fibras com características dimensionais similares cheguem ao alvo. Por fim, os resultados finais esperados (desenvolvimento de inflamações, tumores, etc.) são demorados quando comparados aos resultados analisados por outras rotas [7].

Há várias críticas também em relação à relevância dos resultados de injeção intracavidade (pleural ou peritoneal) e instilação intratraqueal, pois o que se observa na prática é que a exposição às fibras acontece quase na sua totalidade, através de inalação. Outras discordâncias apresentadas são: i) ao se administrar as fibras através das rotas de injeção e instilação, estas não passam através dos mecanismos naturais de remoção, os quais são responsáveis por proteger os pulmões contra materiais inalados; ii) outra desvantagem é que o tempo durante o qual as fibras ficariam normalmente depositadas nas vias respiratórias superiores, para o caso da instilação, é eliminado; iii) para o método de injeção pleural, os tempos de permanência das fibras tanto nas vias respiratórias superiores quanto na traqueia, também são eliminados; iv) outra discordância é que as doses injetadas na maioria das vezes são irrealistas, pois as fibras não poderiam ser acumuladas nestas vias pelos meios fisiológicos naturais [7]. Porém, uma vantagem em se utilizar a técnica de instilação intratraqueal, frente à rota de inalação, está relacionada à garantia da condução de experimentos que apresentam maior repetibilidade e reprodutibilidade em seus resultados. No caso das fibras serem administradas intratraquealmente, a probabilidade de alcance de frações quali e quantitativamente representativas no tecido alvo é maior quando comparada ao processo de inalação. Desta forma, observa-se que as rotas usuais utilizadas na determinação do grau de toxicidade das fibras apresentam vantagens, desvantagens e limitações. Mesmo assim, estas metodologias devem e são utilizadas nas avaliações iniciais de previsão de possíveis patogenicidades desses produtos na espécie humana. A escolha da técnica a ser estudada fica a critério de cada pesquisador.

\section{Classificação da toxicidade dos materiais FCR, AES e $P C W$}

Grande parte dos estudos de toxicidade em relação às fibras minerais feitas pelo homem, mais precisamente para as três categorias de materiais apresentadas neste trabalho, teve início pelo produto FCR, devido ao seu desenvolvimento e comercialização datarem das décadas de 40 e 50, respectivamente. Em um dos primeiros estudos realizados logo após a comercialização das FCRs, foram comparados os efeitos das fibras cerâmicas refratárias no tecido pulmonar com os resultados dos minerais feldspato e calcário. A conclusão foi que os valores de toxicidade das fibras eram menos representativos do que o do mineral feldspato e mais próximos ao material particulado gerado pelo calcário, sendo que este último mineral era classificado como inerte ou não prejudicial aos pulmões [45]. Três décadas mais tarde, as fibras cerâmicas refratárias foram classificadas pela IARC (Agência Internacional de Pesquisas sobre Câncer) $[7,26]$, baseado em diversos experimentos animais e através de diferentes rotas de administração, como substâncias que apresentam evidências do seu grau de patogenicidade em animais, porém em se tratando da espécie humana não há nenhum dado conclusivo. Logo, as FCRs foram classificadas como substâncias possivelmente patogênicas à espécie humana. Uma década após a classificação da FCR pela IARC, a União Europeia em 1997 registrou este material na categoria 2 de patogenicidade [18]; estes produtos deveriam ser tratados como se fossem considerados patogênicos à espécie humana. Esta classificação impôs uma série de obrigações aos fabricantes e usuários das FCR, desde o controle e a redução de exposição às fibras até o desenvolvimento de materiais alternativos e substitutos quando possível.

Objetivando garantir o cumprimento das ações impostas pela União Europeia, a Associação Europeia de Indústrias Fabricantes de FCR (ECFIA) lançou um programa para controle e redução da exposição, CARE, a este material. As indústrias produtoras de FCR estabeleceram um limite de exposição de $1 \mathrm{fibra} / \mathrm{mL}$ de ar para uma média ponderada de $8 \mathrm{~h}$ ao dia durante uma jornada de $40 \mathrm{~h}$ semanais. Isto significava que o trabalhador poderia ser exposto a concentrações superiores ao permitido, contanto que a concentração média ao longo do período ficasse abaixo do valor de referência. Este programa avaliou aproximadamente 720 amostras por ano em todas as etapas de manufatura das FCRs durante o período de 1991 a 1996. Como resultado, 90\% das amostras avaliadas apresentaram valores de concentrações inferiores a 1 fibra/mL [46]. Pesquisadores também mensuraram as concentrações médias de fibras respiráveis de 7 plantas fabricantes de FCR, localizadas na França, Inglaterra e Alemanha. Estes estudos foram realizados em 1987 e posteriormente comparados aos valores obtidos nos anos de 1995 e 1996. A maioria das concentrações das fibras respiráveis ficou abaixo de 0,5 fibra/mL de ar [47]. Atualmente, alguns países reduziram este valor. No caso da França, desde julho de 2009 o 
limite de exposição passou a ser de 0,1 fibra/mL [48]. Sob exigência demandada pela União Europeia em substituir as FCRs, a produção na França passou de 20000 toneladas no início dos anos 1990 a 7500 toneladas em 2004 [49]. Como consequência, os fabricantes de FCR iniciaram a comercialização de outra categoria de fibra, ajustando este material às características físico-químicas definidas pela Comunidade Europeia [18]. Uma destas demandas era que as fibras vítreas sintéticas e com orientação aleatória tivessem um teor ponderal de óxidos de elementos alcalinos e alcalinos terrosos $\left(\mathrm{Na}_{2} \mathrm{O}+\mathrm{K}_{2} \mathrm{O}+\mathrm{CaO}+\mathrm{MgO}+\mathrm{BaO}\right)$ superior a $18 \%$ em massa. Estes produtos receberam a nomenclatura de fibras AES.

As fibras AES são consideradas menos biopersistentes em comparação às FCRs. Os motivos desta baixa durabilidade ainda não foram completamente avaliados. Uma importante regra para gerar uma baixa biopersistência das fibras AES provavelmente seja a redução do número de fibras nos pulmões. Para exposições iguais (quantidade e tempo), quanto menor a durabilidade do material avaliado menor é a dosagem nos pulmões e, consequentemente, uma redução no desenvolvimento de anomalias respiratórias também é alcançada [37]. As duas categorias de materiais, FCR e AES, bem como outros tipos de produtos que fazem parte da nomenclatura "fibras vítreas feitas pelo homem", estão contidas na diretiva da Comunidade Europeia [18]. Outras classes de materiais como as fibras policristalinas (PCW) não foram avaliadas e não possuem nenhuma classificação vinculada a esta diretiva. Em 2007, a diretiva da Comunidade Europeia [18], bem como diversas outras diretivas, foram substituídas pela regulamentação conhecida como REACH (registro, avaliação, autorização e restrição de substâncias químicas na Europa). O objetivo desta lei é o de melhorar a proteção da saúde da espécie humana e do meio ambiente, através da identificação de propriedades intrínsecas de substâncias químicas de forma precoce e efetiva [19]. Em 2010, a União Europeia declarou as FCR como substâncias de alto grau de preocupação e vincularamnas ao anexo XV da REACH. Em 2011, dois tipos de FCR entraram para a lista destas substâncias, sendo estas: fibras cerâmicas refratárias de aluminossilicatos (AFCR) e fibras cerâmicas refratárias à base de zircônia (ZFCR). Os materiais AFCR são, majoritariamente, compostos por óxidos de alumínio e silício, enquanto os produtos de ZFCR apresentam como componentes principais os óxidos de alumínio, silício e zircônio. Ambos os materiais devem possuir o somatório das quantidades de óxidos alcalinos e alcalinos terrosos $\left(\mathrm{Na}_{2} \mathrm{O}+\mathrm{K}_{2} \mathrm{O}+\mathrm{CaO}+\mathrm{MgO}+\mathrm{BaO}\right)$ igual ou inferior a $18 \%$ em massa. Outra característica das fibras é que o diâmetro geométrico médio ponderado em função do comprimento menos dois desvios-padrão deve ser inferior a $6 \mu \mathrm{m}$ [19]. Esta nomenclatura equivalente descrita é uma forma de compensar o efeito sobre a distribuição de diâmetro causada pela ruptura de fibras longas durante o processo de amostragem e/ou manuseio do material.

Ambas as avaliações ocupacionais estudaram as fibras minerais feitas pelos homens após processo de fabricação, não considerando os fatores tempo e temperatura em suas pesquisas. Contudo, vários estudos demonstraram que os materiais FCR e AES quando expostos a determinadas temperaturas e tempos, sofrem o processo de recristalização, sendo que uma das fases formadas é a sílica cristalina, conhecida como cristobalita [5, 12-16, 50]. De acordo com a IARC há evidências suficientes em humanos da patogenicidade da sílica cristalina inalada, nas formas de quartzo ou cristobalita [17]. Além desta constatação, o próprio aspecto relacionado à cristalinidade também é muito importante, uma vez que este parâmetro pode afetar a durabilidade das fibras no tecido alvo [51]. Já para as fibras policristalinas, quando expostas a altas temperaturas, não se observa a formação de cristobalita. O motivo principal é a presença de alta quantidade de alumina $(>70 \%)$ em sua composição química. Apenas as fases mulita e coríndon foram identificadas após tratamento a $1600{ }^{\circ} \mathrm{C}$ [6]. Considerando a presença de cristobalita em equipamentos industriais, a quantidade desta fase presente no interior de um forno industrial de têmpera composto por refratários tradicionalmente empregados (aluminosos e silicoaluminosos) pode ser superior em até 40 vezes quando comparado a um mesmo equipamento que tenha como revestimento as FCRs [1]. Este fato foi constatado conforme a modalidade construtiva e a temperatura de trabalho, representadas na Fig. 8. Para que a comparação apresentada na Fig. 8 fosse realmente efetiva, os revestimentos deveriam ser expostos acima de $900^{\circ} \mathrm{C}$, pois acima deste valor há comprovações da formação da fase cristobalita para revestimentos em FCR. Porém, as observações são válidas e servem de alerta para os possíveis riscos ocupacionais de exposição à fase cristobalita, tanto para revestimentos tradicionais, compostos pelas classes de refratários aluminosos e silicoaluminosos, quanto para revestimentos compostos pelos materiais em FCR e AES.

Desta forma, a avaliação do grau de toxicidade das fibras minerais feitas pelo homem, especificamente as FCR, AES e PCW, após fabricação, mostrou que as FCRs devem ser substituídas, quando possível, por materiais que não possuam os mesmos riscos ocupacionais. As fibras AES não apresentam riscos ocupacionais, conforme avaliação do REACH e IARC e as PCWs não foram classificadas por nenhuma agência ou instituição regulamentadora. Avaliando as três categorias de produtos estudados, após exposição a altas temperaturas (>900 ${ }^{\circ} \mathrm{C}$ ), há a formação da fase cristobalita para os materiais FCR e AES. Esta fase é considerada patogênica à espécie humana pela IARC. Contudo, é importante enfatizar sobre a importância de se desenvolver pesquisas relacionadas à avaliação do grau de patogenicidade das fibras AES, após a confirmação do processo de recristalização e formação da fase cristobalita. Para as fibras PCW, não há evidências da formação de cristobalita, nem mesmo em temperaturas próximas aos valores contínuos de operação de equipamentos, como tampas de panela de aço e gusa e fornos de aquecimento e reaquecimento. 

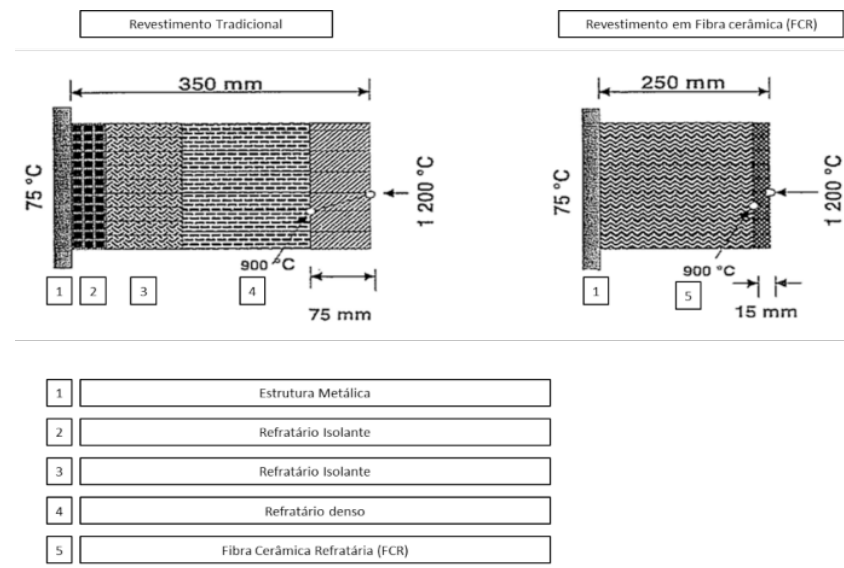

Figura 8: Comparação de um revestimento tradicional versus revestimento com FCR [1].

[Figure 8: Comparison between two linings: common refractory versus FCR [1].]

\section{CONCLUSÕES}

Pôde-se evidenciar através desta revisão que isolantes térmicos fibrosos ocupam um importante papel nos três pilares básicos de sustentabilidade de unidades fabris, em especial da indústria siderúrgica. Em se tratando do quesito econômico, em virtude de suas características físicas, químicas e especiais, os três produtos avaliados (FCR - fibra cerâmica refratária, AES - fibra de silicato de metais alcalino-terrosos, e PCW - fibra policristalina) apresentam vantagens consideráveis quando comparadas aos revestimentos usualmente utilizados (refratários aluminosos e silicoaluminosos). Essas vantagens estão ligadas diretamente à eficiência energética, ou seja, redução da perda de energia pelo refratário, menor quantidade de energia para garantir o encharque do revestimento e rápida resposta no ajuste das temperaturas de tratamento térmico de fornos industriais, especialmente fornos de austenitização e revenimento. Em relação ao quesito disponibilidade dos equipamentos para a área produtiva, os três produtos avaliados apresentam vantagens em relação aos revestimentos usualmente utilizados. Primeiro, devido ao baixo valor de densidade, a sua instalação torna-se mais fácil e rápida, tendo como possível consequência uma redução nos tempos despendidos durante as manutenções. Outra característica é a alta resistência ao choque térmico. Este aspecto permite que o equipamento possa ser resfriado e aquecido em taxas superiores às adotadas para refratários aluminosos e silicoaluminosos, sem ocasionar fraturas catastróficas no revestimento e, consequentemente, paradas não programadas. No quesito risco ocupacional, as fibras FCR foram classificadas como substâncias possivelmente patogênicas à espécie humana. Porém, vale ressaltar que, na mesma classe apresentada pela IARC, estão materiais como o café, telefone celular, vegetais em conserva, fumos metálicos e gasolina. As fibras AES apresentam baixo risco à espécie humana. Contudo, recomenda-se por aspectos ocupacionais, que este produto seja utilizado em temperaturas inferiores a
$900{ }^{\circ} \mathrm{C}$. As fibras PCW não foram classificadas por nenhuma agência reguladora. Os fabricantes das fibras PCW creditam esta falta de classificação, ao controle mais preciso das dimensões das fibras durante a fabricação. Este aspecto gera um produto com menor quantidade de material particulado considerado respirável, de acordo com as premissas adotadas pela Organização Mundial de Saúde.

\section{AGRADECIMENTOS}

Ao grupo Vallourec e Nippon Steel \& Sumitomo Metal Corporation pelo apoio no desenvolvimento deste trabalho. Às instituições de fomento à pesquisa CAPES, CNPQ e FAPEMIG.

\section{REFERÊNCIAS}

[1] G. Sonnenschein, Gefahrst. Reinhalt. L. 63, 5 (2003) 181-185.

[2] H. Wimmer, Gaswarme Int. 53, 5 (2004) 273-278.

[3] Nippon Steel Tech. Report 98 (1998) 110-115.

[4] Am. Soc. Test. Mater., ASTM C892, "Standard specification for high-temperature fiber blanket thermal insulation”, Estados Unidos (1993).

[5] Verein Deutscher Ingenieure, VDI-3469, part 5, Production and processing of fibrous materials, Dusseldorf, (2007).

[6] T. Tonnesen, R. Telle, in $46^{\text {th }}$ Int. Colloq. Refractories, Aachen (2003) 149.

[7] Int. Ag. Res. Cancer (IARC) Vol. 81, Lyon (2002).

[8] B. Bellmann, H.A. Schaeffer, H. Muhle, Ann. Occup. Hyg. 46 (2002) 166-169.

[9] R.C. Brown, B. Bellmann, H. Muhle, H. Ernst, G. Pohlmann, P. Sébastien, Ann. Occup. Hyg. 46 (2002) $102-$ 104.

[10] T.W. Hesterberg, G.A. Hart, J. Chevalier, W.C. Miller, R.D. Hamilton, J. Bauer, P. Thevenaz, Toxicol. Appl. Pharm. 153 (1998) 68-82.

[11] R.C. Brown, P.T.C. Harrison, Regul. Toxicol. Pharm. 64 (2012) 296-304.

[12] P. Comodi, F. Cera, G.D. Gatta, N. Rotiroti, P. Garofani, Ann. Occup. Hyg. 54 (2010) 893-903.

[13] A.F Gualtieri, E. Foresti, I.G. Lesci, N. Roveri, M. L. Gulatieri, M. Dondi, M. Zapparoli, J. Hazard. Mater. 162 (2009) 1494-1506.

[14] G. Binde, T. Bolender, Gefahrst. Reinhalt. L. 62, 6 (2002) 273-278.

[15] D.J. Dyson, M.A. Butler, R. Fisher, R.J. Hughes, G.W. Hicks, Ann. Occup. Hyg. 41, 5 (1997) 561-590.

[16] J.J. Laskowski, J. Young, R. Gray, R. Acheson, S.D. Forder, Anal. Chim. Acta 286 (1994) 9-23.

[17] Int. Ag. Res. Cancer (IARC) Vol. 68, Lyon (1997) 521. [18] Eur. Comission Directive 97/69/EC (1997) 19-24.

[19] Registration, evaluation, authorization and restriction of chemicals (REACH) <http://ec.europa.eu/environment/ chemicals/reach_en.htm>, acesso 12/03/2016.

[20] L. Kiakouama, D. Faucon, Archives des Maladies 
Professionnelles et de L'Environnement 71 (2010) 759-770. [21] Eur. Comm. Standardization, EN 1094-1, "Insulating refractory products - terminology, classification and methods of test for high temperature insulation wool products", Bruxelas (2008).

[22] Bundesanstalt für Arbeitsschutz und Arbeitsmedizin, "Technical rules for hazardous substances, TRGS 619, Substitute materials for aluminium silicate wool products", Alemanha (2007).

[23] E. Horie, Ceramic fiber insulation theory and practice, Eibun Press, Osaka (1987) 25.

[24] C.V. Santilli, S.H. Pulcinelli, R.S. Hiratsuka, Quím. Nova 18, 2 (1995) 171-180.

[25] J.W.S. Hearle, High performance fibres, Woodhead Publishing, Cambridge (2001) 248.

[26] Int. Ag. Res. Cancer (IARC) vol. 43, Lyon (1988).

[27] L.D. Maxim, W.P. Kelly, T. Walters, R. Waugh, Regul. Toxicol. Pharm. 20 (1994) 200-215.

[28] HTIW Coalition, http://www.htiwcoalition.org, acesso 10/03/2015.

[29] Inst. Aço Brasil, http://www.acobrasil.org.br, acesso 15/05/2014.

[30] Plano da Comissão Europeia, Europa 2020, http:// ec.europa.eu/europe2020index_en.htm, acesso 20/06/2014 .

[31] H. Wimmer, in 54 $4^{\text {th }}$ Int. Colloq. Refractories, Eur. Centre Refractories, Aachen (2011).

[32] M. Schnabel, A. Buhr, G. Buchel, R. Kockegey-Lorenz, J. Button, Refractories Worldforum Mag. 3 (2011) 87-94.

[33] Am. Soc. Test. Mater., ASTM C155, "Standard classification of insulating firebrick", Estados Unidos (1997) 2.

[34] A. Overhoff, A. Buhr, J. Grass, H. Wuthnow, cfi/Ber. DKG 82, 8 (2005) E1-E5.

[35] R.A. McCauley, Corrosion of ceramic and composite materials, 2a ed., Marcel Dekker, Nova Iorque (2004) 263.
[36] M.S. Crowley, in Handbk. Sci. Tech. Alumina Chem., $1^{\text {st }}$ ed., Wiley - Am. Ceram. Soc., EUA (1990) 471-488.

[37] P. Class, P. Deghilage, R.C. Brown, Ann. Occup. Hyg. 45, 5 (2001) 381-384.

[38] Am. Petroleum Inst., API 560, "Refractory lining and burner brick requirements", Estados Unidos (2011) 29.

[39] World Health Org. (WHO), "Determination of airborne fibre number concentrations: a recommended method, by phase contrast optical microscopy (membrane filter method)", Genebra (1996) 52.

[40] T.W. Hesterberg, G.A. Hart, Crit. Rev. Toxicol. 31 (2001) 1-53.

[41] B.G. Miller, A. Searl, J.M. Davis, K. Donaldson, R.T. Cullen, R.E. Bolton, Ann. Occup. Hyg. 43, 3 (1999) 155166.

[42] D.M. Bernstein , C. Morscheidt, H.G. Grimm, P. Thévenaz, U. Teichert, Inhal. Toxicol. 8 (1996) 345-385.

[43] R.O. McClellan, T.W. Hesterberg, Environ. Health Persp. 102 (1994) 277-283.

[44] R.C. Brown, B. Bellmann, H. Muhle, J.M.G. Davis, L.D. Maxim, Ann. Occup. Hyg. 49, 4 (2005) 295-307.

[45] P. Gross, M.L. Westrick, H.H. Schrenk, J.M. McNerney, Am. Med. Assoc. 13 (1956) 161-166.

[46] C.G. Burley, R.C. Brown, L.D. Maxim, Ann. Occup. Hyg. Ann. Occup. Hyg. 41 (1997) 267-272.

[47] B.G. Miller, J.W. Cherrie, S. Groat, E. Kauffer, Ann. Occup. Hyg. 51, 6 (2007) 501-507.

[48] Decreto $n^{\circ}$ 2007-1539, https://www.legifrance.gouv.fr, acesso 10/09/2015.

[49] Nat. Inst. Occup. Safety Health (NIOSH) 123, Estados Unidos (2006) 203.

[50] S.Y. Zhao, X.D. He, B.M. Zhang, S.Y. Du, Compos. Sci. Technol. 71 (2011) 415-423.

[51] Int. Ag. Res. Cancer (IARC), Sci. Publ. n 140, Lyon (1996) 4.

(Rec. 18/04/2016, Rev. 11/08/2016, Ac. 28/02/2017) 